\title{
Article \\ Global DNA 5hmC and CK195hm+ Contents: A Promising Biomarker for Predicting Prognosis in Small Hepatocellular Carcinoma
}

\author{
Jinhua Jiang ${ }^{1,2}$, Tinghua Yan ${ }^{3}$ and Fang Guo ${ }^{1, *}$ \\ 1 Key Laboratory of Systems Biomedicine, Ministry of Education, Shanghai Center for Systems Biomedicine, \\ Shanghai Jiao Tong University, Shanghai 200240, China; carli8880@sjtu.edu.cn \\ 2 Department of Interventional Oncology, Renji Hospital, School of Medicine, Shanghai Jiaotong University, \\ Shanghai 200127, China \\ 3 Department of Interventional Oncology, The First Clinical Medical College of Jinan University, \\ Guangzhou 510660, China; tinghua@stu.jnu.edu.cn \\ * Correspondence: fguo@sjtu.edu.cn
}

check for

updates

Citation: Jiang, J.; Yan, T.; Guo, F. Global DNA 5hmC and CK19 $5 \mathrm{hmC}+$

Contents: A Promising Biomarker for

Predicting Prognosis in Small

Hepatocellular Carcinoma. Curr.

Oncol. 2021, 28, 3758-3770. https://

doi.org/10.3390/curroncol28050321

Received: 23 August 2021

Accepted: 23 September 2021

Published: 28 September 2021

Publisher's Note: MDPI stays neutral with regard to jurisdictional claims in published maps and institutional affiliations.

Copyright: (C) 2021 by the authors Licensee MDPI, Basel, Switzerland. This article is an open access article distributed under the terms and conditions of the Creative Commons Attribution (CC BY) license (https:// creativecommons.org/licenses/by/ $4.0 /)$.

\begin{abstract}
Background: 5-Hydroxymethylcytosine (5hmC) with dynamic existence possesses multiple regulatory functions. Whereas, $5 \mathrm{hmC}^{\prime}$ s impact on small hepatocellular carcinoma (SHCC) remains unclear. The present work focused on characterizing $5 \mathrm{hmC}$ content within SHCC and assessing the possibility of using global genomic $5 \mathrm{hmC}$ level as the predicative factor of clinical outcome. Methods: This study applied ultra-high-performance liquid chromatography-tandem mass spectrometry (UHPLC-MS/MS) in measuring $5 \mathrm{mC}, 5 \mathrm{fC}$ and $5 \mathrm{hmC}$ contents. In addition, immunohistochemistry (IHC) was adopted to measure CK19 and 5hmC contents. Results: Research showed 5mC, 5hmC, and $5 \mathrm{fC}$ contents from global genomics of SHCC reduced extensively compared with healthy samples $(p<0.001)$. Moreover, SHCC was associated with lymph node metastasis (LNM). Greater 5mC and $5 \mathrm{hmC}$ levels were observed in non-metastasis group compared with the metastasis group $(p<0.001)$. Correlation analysis between the HBV DNA level and $5 \mathrm{mC}, 5 \mathrm{fC}$ and $5 \mathrm{hmC}$ levels exhibited that HBV DNA was associated with $5 \mathrm{mC}, 5 \mathrm{hmC}$, and $5 \mathrm{fC}$ content reduction, which was verified in the cytological experiments. Moreover, $5 \mathrm{hmC}$ content had a negative correlation with the expression level of CK19 in SHCC. The decrease in 5hmC and CK19 containing 5hmC positive cell (called CK1 $19^{5 \mathrm{hmC}+}$ ) should be ascribed to the bad prognosis among SHCC patients. Conclusions: The contents of $5 \mathrm{hmC}$ and CK195 ${ }^{5 \mathrm{hmC}+}$ of genomic DNA might be adopted for predicting SHCC survival as an important biomarker.
\end{abstract}

Keywords: small hepatocellular carcinoma; CK19; 5hmC; DNA methylation; prognosis

\section{Background}

As the world's sixth leading tumor, hepatocellular carcinoma (HCC) has been classified among those frequently occurring hypervascular cancers featuring neovascularization [1]. Inadequate response toward conventional therapies, recurrence, as well as metastasis frequently occurs in HCC related to bad prognostic outcome. The HCC-related risk factors encompass chronic hepatitis B/C virus (HBV/HCV) infection, smoking, alcoholism, obesity, diabetes, and dietary aflatoxin [2]. HCC is mostly detected in terminal and lethal stages. Thus, the development of screening methods for early diagnosis seems imperative.

As HCC screening approaches are continually improved, the detection rate for small hepatocellular carcinoma (SHCC) is elevated. In accordance with the Asia Pacific Society's guide on the research concerning liver illnesses as well as the standard guide for the pathological diagnosis of HCC, a single tumor whose diameter is $\leq 3 \mathrm{~cm}$ can be determined to be SHCC [3,4]. It is usually considered the HCC with good prognosis because of distinctive biological behavior and pathological features. Currently, HCC detection is mainly 
accomplished using AFP, ultrasonography, CT, or other diagnostic approaches, involving minor constraints [5]. DNA methylation, among the earliest epigenetic modifications, is considered the crucial section that can maintain gene imprinting, $\mathrm{X}$-chromosome silence, chromosome structure, as well as cancer genesis [6,7]. Investigation of the effect of DNA methylation, the underlying mechanism, as well as their differences of different people or tissue samples can incisively influence disease study and human health. Methylation of genomic DNA, an important manner for epigenetic modification, is playing a key role in biological process regulation, such as cell differentiation or gene levels [8-10]. Thus, epigenetic mechanism exerts functions in SHCC pathogenesis as well as maintenance.

DNA methylation for cytosine at the 5-position $(5 \mathrm{mC})$ serves as a kind of epigenetic cancer marker. Multiple reports have demonstrated that the protein family of ten-eleven translocations (TET) can initiate the DNA demethylation-associated pathway, resulting in $5 \mathrm{mC}$ transformation in the 5-hydroxymethylcytosine (5hmC) [11], the promising epigenetic biomarker that can alter tumor epigenetic prospects. Research results consider reduced $5 \mathrm{hmC}$ contents as a manifestation for poor prognosis among cases suffering malignancies in the digestive system $[12,13]$. Whereas epigenetic research concerning $5 \mathrm{hmC}$ in SHCC has not been completed to date. Meanwhile, 5-formylcytosine (5fC) is also a product of sequential oxidation of $5 \mathrm{mC}$ by TET. Further, $5 \mathrm{fC}$ is finally transformed into unmethylated cytosine via base excision repair, finishing the demethylation process [14]. It has been estimated that the abundant $5 \mathrm{fC}$ is $10-1000$ fold less than $5 \mathrm{hmC}$, suggesting that $5 \mathrm{fC}$ is the short-lived intermediate during the active demethylation process [11]. Whereas, several proteins are seemingly bound to $5 \mathrm{fC}$, specifically, which indicated that it could also possess an independent epigenetic signaling function [15].

CK19 serves as a major intermediate filament whose molecular weight is approximately $40 \mathrm{kDa}$. cytokeratin 19 (CK19), as a critical marker for proliferative subtype, suggests the bad prognosis among HCC patients [16]. Around 10-30\% HCC patients exhibit CK19 expression [17]. CK19-positive HCC, also called biphenotypic HCC, has pathological characteristics of HCC and cholangiocarcinoma (CC). The patients usually exhibit worse results than CK19-negative HCC patients. Thus, CK19 is the prognostic marker of HCC. Moreover, a recent study has showed that serum CK19 levels, associated to AFP and PIVKA-II, may be useful to stratify survival of patients with HCC in Patients with Hepatocellular Carcinoma [18], highlighting the importance of CK19 as a prognostic marker. Whereas, CK19's prognostic value in combination with other marker has never been fully appreciated.

In this study, UHPLC-MS/MS as well as immunohistochemistry (IHC) staining was employed for analyzing $5 \mathrm{mC}, 5 \mathrm{fC}$ and $5 \mathrm{hmC}$ levels of genome-wide DNA and CK19, thus assessing its association with SHCC-related clinical features and survival results. Our results showed that the contents of $5 \mathrm{hmC}$ and $\mathrm{CK} 19^{5 \mathrm{hmC}+}$ of genomic DNA might be adopted for predicting SHCC survival as an important biomarker.

\section{Methods}

\subsection{Study Design and Specimens}

The research aimed to evaluate DNA hydroxy methylcytosine's clinical features of SHCC. This study used UHPLC-MS/MS in studying 5hmC content, and molecular classification was performed using IHC. During January 2010 and December 2012, sixtythree SHCC patients participated in the study at Shanghai Renji Hospital. Clinical data, such as gender, age upon diagnosis, and tumor volume could be retrospectively obtained from medical records. Patients were followed up via phone or outpatient counselling. This research follows the Code of Ethics of the World Medical Association (Declaration of Helsinki). This research was ratified by the Ethics Committee in Shanghai Renji Hospital, Shanghai Jiaotong University, and informed consent had been provided by patients.

Tumor samples were gathered prior to adjuvant treatment in the first surgery. All samples were subjected to snap freezing under $-80^{\circ} \mathrm{C}$ or fastening in formalin buffer $(4 \%)$, 
followed by paraffin embedding. As for the controls, this study obtained normal liver tissues at the School of Life Sciences, Shanghai Renji Hospital.

\subsection{Assessment about Global Genomic $5 \mathrm{mC}$, $5 f \mathrm{C}$ and $5 \mathrm{hmC}$ Contents Using UHPLC-MS/MS}

The $5 \mathrm{mC}, 5 \mathrm{fC}$ and $5 \mathrm{hmC}$ contents of SHCC were measured as mentioned above. Briefly, the Wizard ${ }^{\circledR}$ Genomic DNA Purification Kit (A1620, Promega, Madison, WI, USA) was utilized to separate DNA. DNA ( $1 \mu \mathrm{g} /$ sample) received heating treatment under $100^{\circ} \mathrm{C}$ for $180 \mathrm{~s}$, followed by $6 \mathrm{~h}$ of incubation using nuclease P1 (2U, Sigma, N8630, Darmstadt, Germany) under $42{ }^{\circ} \mathrm{C}$ and the addition of alkaline phosphatase (1 U, Sigma, M183A) for another $6 \mathrm{~h}$ of incubation under $37^{\circ} \mathrm{C}$. After diluting to $0.06 \mathrm{~mL}$ before filtering $(0.45 \mu \mathrm{m}$, PALL), nucleoside extraction was performed using the T3 column (186003538, WATERS, Milford, MA, USA) with UHPLC, followed by detection by triple-4 quadrupole mass spectrometer (ACQUITY UPLC XEVO TQ-S, WATERS). Thereafter, the mass transitions $\mathrm{m} / \mathrm{z} 258.2$ to 124.2 (hmC), m/z 242.3 to 126.1 (mC), and m/z 228.4 to 112.2 (C) were monitored and documented. Levels could be acquired via a comparison on standardized curves for pure nucleoside standards and samples from the same batch.

\subsection{CK19 and 5hmC Contents Measured by IHC}

In brief, tissues were sectioned $(5 \mu \mathrm{m})$, de-paraffinized, and re-hydrated using ethanol and xylene. Slides were treated for 10 min with $3 \% \mathrm{H}_{2} \mathrm{O}_{2}$ within the PBS to weaken the activity of endogenous peroxidase, followed by overnight incubation using rabbit monoclonal anti-CK19 antibody (1:1500, ab15580) and anti-5hmC (1:800, ab214728) antibody according to specific Leica Bond protocols IHC-F. Additionally, this study employed a Leica Bond Polymer Refine DAB detection kit for instruction. Two hepatologists evaluated overall IHC slides; corresponding scoring approaches were carried out as introduced by the former report [9].

According to CK19 or $5 \mathrm{hmC}$ positive staining, if more than $80 \%$ cells displayed nuclear positivity, the cells were scored positive and negative otherwise.

\subsection{IHC Analysis of $5 \mathrm{hmC}$ and CK19}

The protein expression of CK19 and $5 \mathrm{hmC}$ in tumor tissues was measured using IHC. Then, we sliced samples embedded in paraffin in the 4- $\mu \mathrm{m}$ sections, followed by deparaffinage using xylene as well as rehydration with gradient ethanol. Samples were later suspended within EDTA antigenic retrieval buffer for 15 min. Further, $3 \% \mathrm{H}_{2} \mathrm{O}_{2}$ with absolute methanol was used to block the activity of endogenous peroxidase for $20 \mathrm{~min}$. In addition, 5\% BSA was added to prevent non-specific binding for $15 \mathrm{~min}$. Primary antibodies against CK19 (1:1500, ab15580), 5mC (1:200, ab10805), and 5hmC (1:800, ab214728) were provided by Abcam. Then, sections received incubation overnight under $4{ }^{\circ} \mathrm{C}$ using primary antibodies against CK19. After overnight incubation at $4{ }^{\circ} \mathrm{C}$, rinse with PBS for 3 times for $5 \mathrm{~min}$ each time. Then biotinylated secondary antibody was added, incubate the slices at room temperature for $10 \mathrm{~min}$, and then rinse with PBS for 3 times for $5 \mathrm{~min}$ each time. Subsequently, streptomyces avidin alkaline phosphatase dropwise was added and the slice was incubated at room temperature for $10 \mathrm{~min}$, and then rinsed with PBS for 3 times for 5 min each time. Alkaline phosphatase chromogenic solution (BCIP/NBT) chromogenic solution (purple blue) was added. Wash with PBS for 3 times for 5 min each time. Wash with PBS for 3 times for 5 min each time. Then $0.05 \%$ hydrochloric acid dropwise was added for $10 \mathrm{~min}$ at room temperature. Following the above steps, $5 \mathrm{hmC}$ antibody was added and the slices were incubated overnight at $4{ }^{\circ} \mathrm{C}$ before rinsing with PBS for 3 times for $5 \mathrm{~min}$ each time. Then biotinylated secondary antibody was added, incubate the slices at room temperature for $10 \mathrm{~min}$, and then rinse with PBS for 3 times for $5 \mathrm{~min}$ each time. Subsequently, streptomyces avidin alkaline phosphatase dropwise was added and the slice was incubated at room temperature for $10 \mathrm{~min}$, and then rinsed with PBS for 3 times for 5 min each time. Wash with PBS for 3 times for 5 min each time. Peroxidase chromogenic solution (3,30-diaminobenzidine tetrachloride) chromogenic solution was added before 
washing with PBS for 3 times for 5 min each time. Hematoxylin was used to counterstain the nucleus. The slices were sealed before observation using an inverted microscope (Leica, Wetzlar, Germany). Water soluble sealing agent. In addition, this study also employed the scoring and staining approaches according to the above description. In brief, dark brown color belonged to positive staining, while negative staining was reflected as fine granular or scant or no background staining. Taking nuclear area for analysis since the CK19 has membrane staining, average value for five snapshots was gained for showing positive cells' percentage. In accordance with positively stained cells' percentage, these sections could be rated as $0(\leq 5 \%), 1(6-25 \%), 2(26-50 \%), 3(51-75 \%)$ and $4(>76 \%)$. Likewise, sample was rated using the staining intensity, with $0,1,2$ and 3 indicting negative, weakly positive, moderately positive and strongly positive staining, respectively. Then, the overall immuno-reactive score sin every sample (0-12) were measured through the multiplication of positive cell percentage score with staining intensity score. Then, all samples could be divided into high (4-12) or low (0-3) expression group.

\subsection{Data Analysis}

Data analysis was made with SPSS23.0 (IBM Corp., New York, NY, USA). $p<0.05$ (two-sided) indicated statistical significance. Data were indicated by median (minimummaximum) or mean $\pm \mathrm{SD}$. Variable normality was evaluated. $t$-test and Mann-Whitney $\mathrm{U}$ test were conducted for assessing differences of mean and median. Relationship among categorical variables was evaluated by Fisher's exact test. The $5 \mathrm{hmC}$ content could be classified into two groups by Cut off Finder to analyze the association between the $5 \mathrm{hmC}$ content and patients' unfavorable prognosis. Cutoff values $(0.102 \%)$ constituted points showing obvious grouping, including OS and DFS.

OS was measured between the initial surgical resection performed at pathological diagnosis and death, whereas DFS between the first diagnosis (at initial therapy) and initial tumor recurrence. OS and DFS Kaplan-Meier curves were documented. Then, log-rank tests were conducted to test the clinical and demographic differences between OS and DFS.

\section{Results}

\subsection{Clinical Characteristics}

Sixty-three patients ( 7 females and 56 males) were enrolled in this study, and primary SHCC and para-tumor tissues were gathered for further investigation. The patients maximum tumor diameters were $\leq 3 \mathrm{~cm}$, till A or B stages (BCLC staging). Most patients suffered HBV. CK19 content was very low in HCC samples $[17,18]$. During the research, CK19 expression level among 46 patients out of a total of 63 was measured. The missing data for the rest of patients did not affect the results of studies. Table 1 illustrates detailed clinicopathological data.

Table 1. Clinical characteristics in SHCC.

\begin{tabular}{ll}
\hline Characteristics & Value \\
\hline Demographics & \\
Patient No. & 63 \\
Age (years) & 40 \\
$\geq 50$ & 23 \\
$<50$ & $56 / 7$ \\
Gender (male/female) & \\
Tumor volume (cm) & 26 \\
$\leq 2$ & 37 \\
$2-3$ & 45 \\
AFP(mg/mL) & 18 \\
$\leq 25$ & \\
$>25$ & \\
\hline
\end{tabular}


Table 1. Cont.

\begin{tabular}{ll}
\hline Characteristics & Value \\
\hline CK19 index & \\
$<25 \%$ & 20 \\
$\geq 25 \%$ & 26 \\
HBV DNA(IU/mL) & \\
$<10^{3}$ & 36 \\
$\geq 10^{3}$ & 27 \\
Cirrhosis & \\
Yes & 42 \\
NO & 21 \\
BCLC classification & \\
0 & 18 \\
A & 35 \\
B & 10 \\
Relapse & 29 \\
\hline
\end{tabular}

Acronyms: SHCC, small hepatocellular carcinoma; HBsAg, HBV surface antigen; HBeAg, HBV e antigen; AFP, alpha-fetoprotein; CK19, Cytokeratin 19; 5mC, 5- methylcytosine; 5hmC, 5-hydroxymethylcytosine; BCLC classification, Barcelona Clinic Liver Cancer classification.

\subsection{Genome-Wide $5 \mathrm{mC}, 5 f \mathrm{C}$ and $5 \mathrm{hmC}$ Levels during SHCC Metastasis}

UHPLC-MS/MS was used for determining $5 \mathrm{mC}, 5 \mathrm{hmC}$, and $5 \mathrm{fC}$ contents of 63 pairs of SHCC as well as matched healthy samples and assessing global changes. Differences in $5 \mathrm{mC}, 5 \mathrm{fC}$ and $5 \mathrm{hmC}$ levels could be detected in SHCC as well as normal samples. The $5 \mathrm{mC}, 5 \mathrm{fC}$ and $5 \mathrm{hmC}$ levels of cancer samples considerably decreased in contrast to healthy samples $(p<0.001)$ (Figure 1A,C,E).

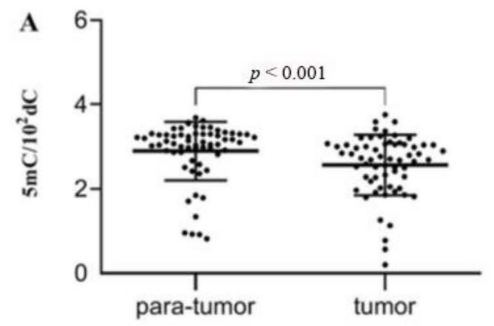

D

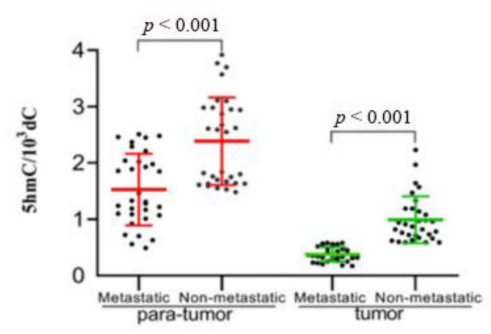

B

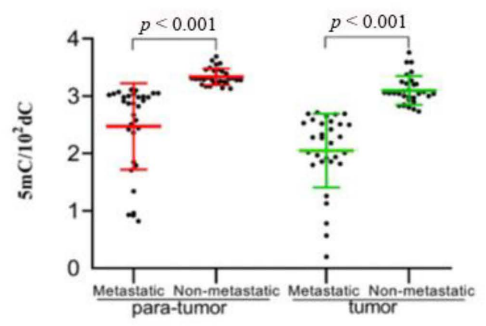

$\mathbf{E}$

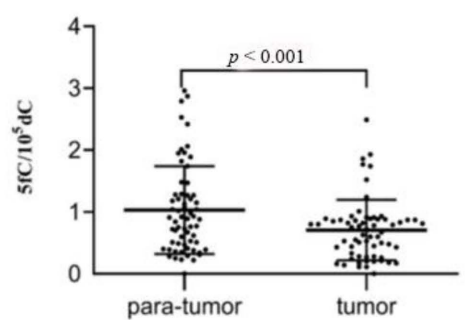

C

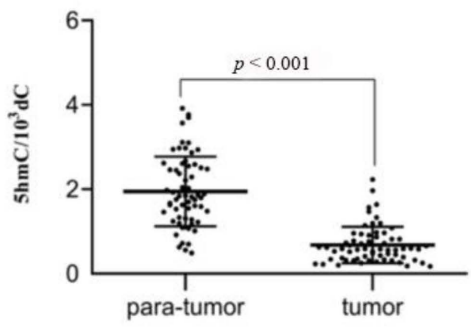

$\mathbf{F}$

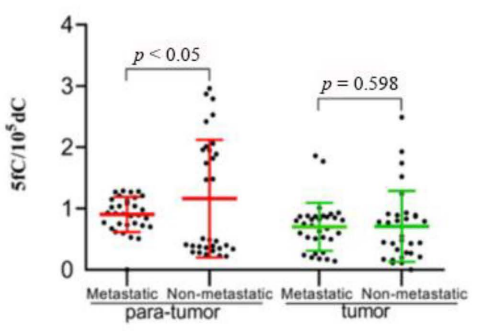

Figure 1. The $5 \mathrm{mC}, 5 \mathrm{fC}$ and $5 \mathrm{hmC}$ levels of global genome reduced in SHCC. Genome-wide DNA extraction was made in SHCC and corresponding healthy samples among 63 cases and used for 5mC, 5fC and 5hmC UHPLC-MS/MS observation. The $5 \mathrm{mC}(\mathbf{A}), 5 \mathrm{hmC}$ (C), $5 \mathrm{fC}$ (E) levels in every sample have been given. The $5 \mathrm{mC}, 5 \mathrm{fC}$ and $5 \mathrm{hmC}$ levels obviously declined within metastasis SHCC tissues in comparison with para-tumor tissues (A,C,E). Obvious changes in $5 \mathrm{hmC}$ and $5 \mathrm{mC}$ levels were observed in SHCC and normal samples during metastasis (B,D). The $5 \mathrm{fC}$ contents during metastasis in SHCC para-tumor tissues continually decreased obviously in comparison with non-metastasis. No remarkable distinctions were observed from SHCC tissues (F). p-value from statistical analysis comparing different groups is also indicated.

To further study if there were obvious changes in $5 \mathrm{mC}, 5 \mathrm{fC}$ and $5 \mathrm{hmC}$ contents during SHCC metastasis, we measured their levels. Research proved that the contents of all the 
three contexts in SHCC metastasis tissue obviously decreased in comparison with paratumor tissues. However, among the three contexts, $5 \mathrm{mC}$ and $5 \mathrm{hmC}$ contents during SHCC metastasis tissue changed more significantly than para-tumor tissues compared with $5 \mathrm{fC}$ (Figure 1B,D,F).

\subsection{Decreased $5 \mathrm{mC}$, $5 f C$ and $5 \mathrm{hmC}$ Levels within SHCC Genome Associated with HBV DNA Level}

HBV DNA level of blood reflects immediate HBV infection. According to HBV DNA level, patients fell into two groups, to analyze $5 \mathrm{mC}, 5 \mathrm{fC}$ and $5 \mathrm{hmC}$ contents in every group. Research proved the more drastic decline of $5 \mathrm{mC}, 5 \mathrm{fC}$ and $5 \mathrm{hmC}$ contents of the HBV DNA-high group than the HBV DNA-low group (Figure 2A,C,E).
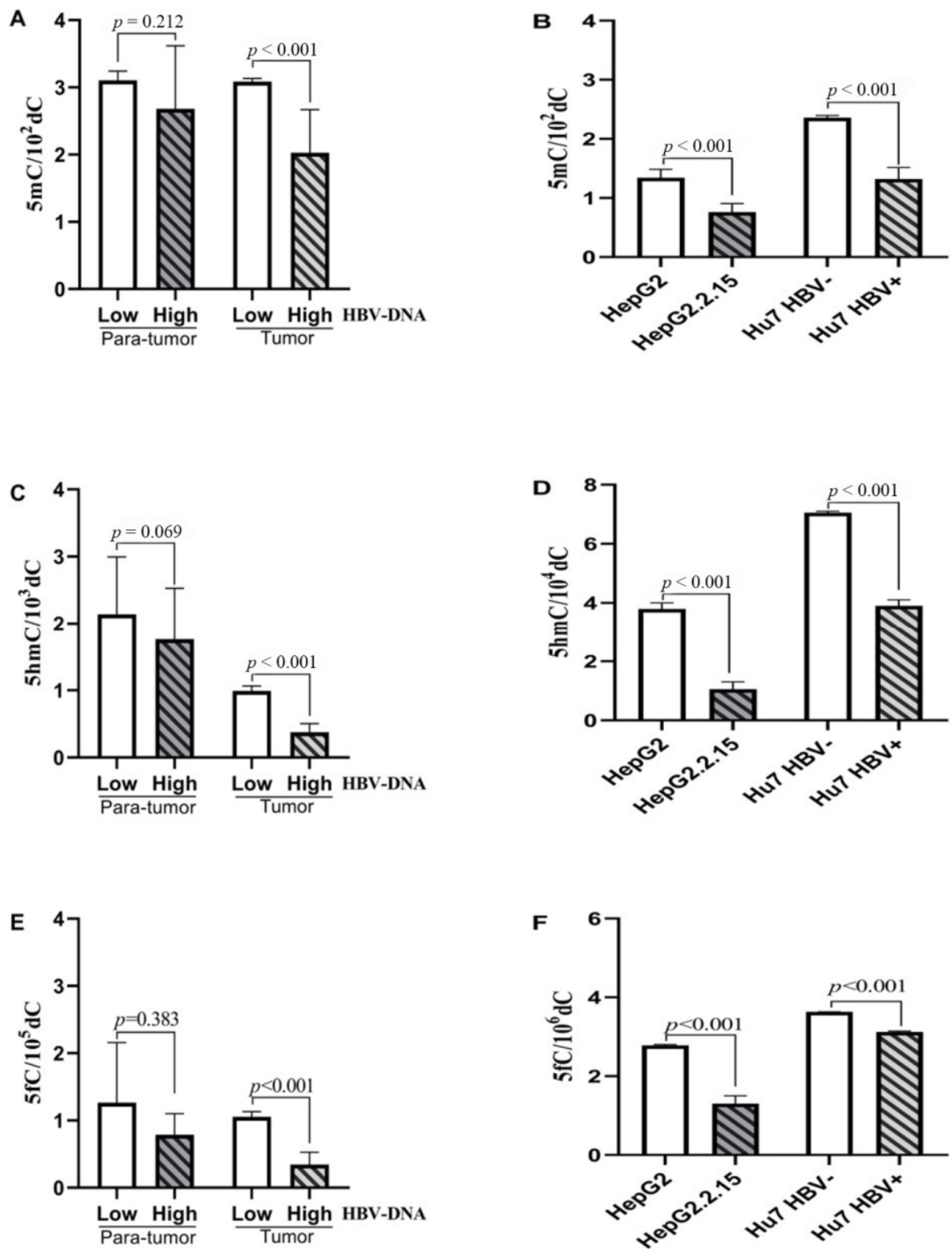

Figure 2. The genomic $5 \mathrm{mC}, 5 \mathrm{fC}$ and $5 \mathrm{hmC}$ levels within SHCC Genome Associated with HBV DNA Level. The genomic $5 \mathrm{mC}, 5 \mathrm{fC}$ and $5 \mathrm{hmC}$ levels obviously declined in the HBV DNA-high group than the HBV DNA-low group of SHCC tissues $(\mathbf{A}, \mathbf{C}, \mathbf{E})$. The genomic $5 \mathrm{mC}, 5 \mathrm{fC}$ and $5 \mathrm{hmC}$ levels obviously decreased in HepG2.2.15 and Hu7 HBV+ cells in comparison with the original cell lines $(\mathbf{B}, \mathbf{D}, \mathbf{F})$.

To further validate whether $\mathrm{HBV}$ infection could reduce the content of $5 \mathrm{mC}, 5 \mathrm{fC}$ and 5hmC, this study adopted two HCC cell lines and HBV DNA (HepG2.2.15 and Hu7 HBV ${ }^{+}$) 
and also the counterpart cell lines without the HBV DNA (HepG2 and Hu7 HBV ${ }^{-}$). As indicated by the research, the genomic $5 \mathrm{mC}, 5 \mathrm{fC}$ and $5 \mathrm{hmC}$ levels obviously decreased in those two cells mentioned above in comparison with the original cell lines (Figure 2B,D,F). Generally, the results demonstrated reduced $5 \mathrm{fC}$ and $5 \mathrm{hmC}$ contents within SHCC tumor tissues of genomic DNA, and HBV infection may lead to more serious abnormality.

\subsection{Global Genomic 5hmC Content Negatively Correlated with the CK19 Positive Cells}

For testing the assumption that $5 \mathrm{hmC}$ reduced within $\mathrm{SHCC}$, while obviously declined within metastatic samples, the experiment detected 5hmC content as well as CK19 expression in SHCC tissue by immunohistochemistry (IHC). As a result, $5 \mathrm{hmC}$ and CK1 $19^{5 \mathrm{hmC}+}$ levels decreased within SHCC metastatic tissues compared with non-metastasis tissues. Besides, the expression level of CK19 was up-regulated for SHCC metastasis tissues while down-regulated for non-metastasis tissues (Figure $3 \mathrm{~A}$ ).

A

A
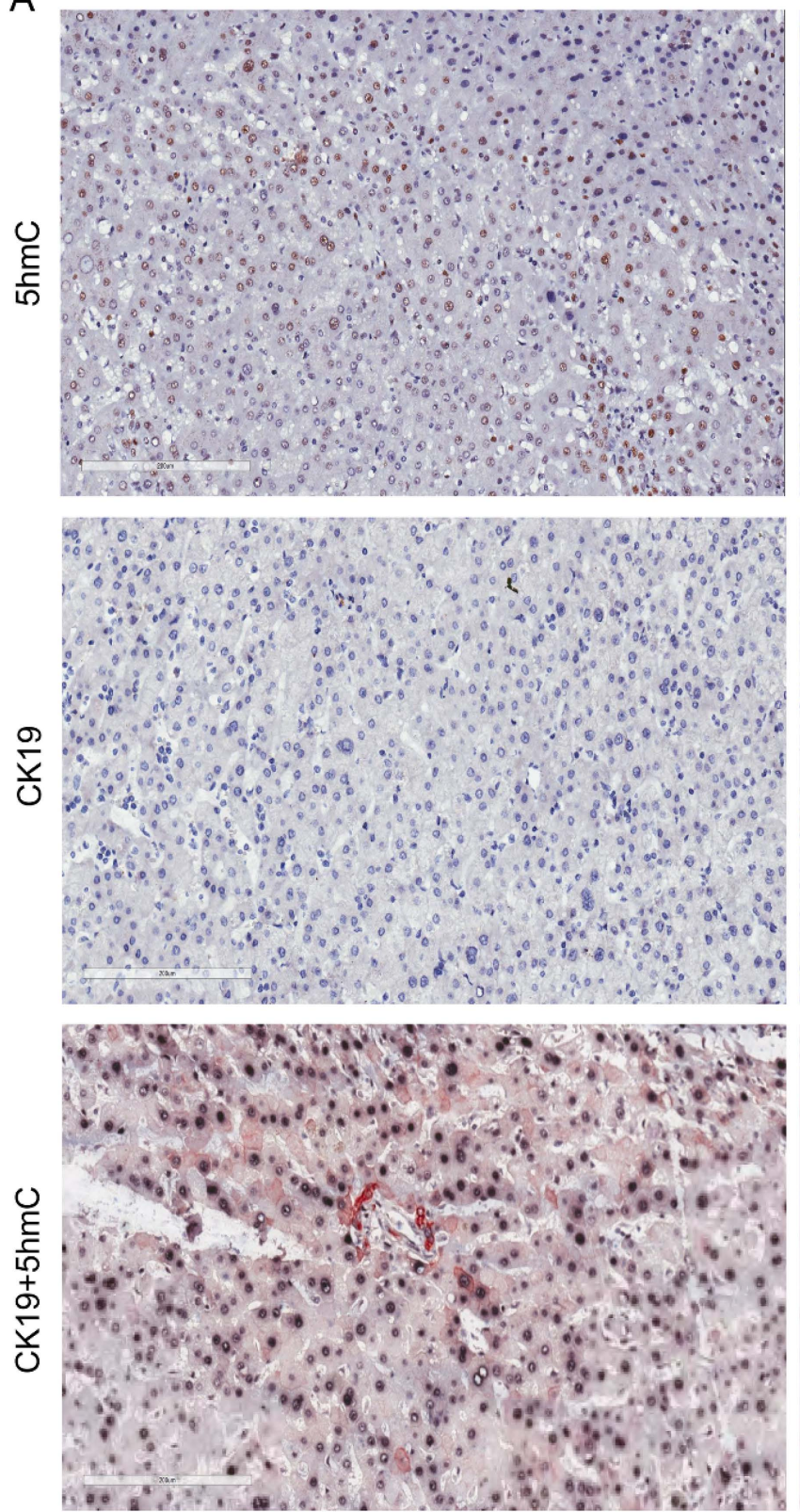

Tumor
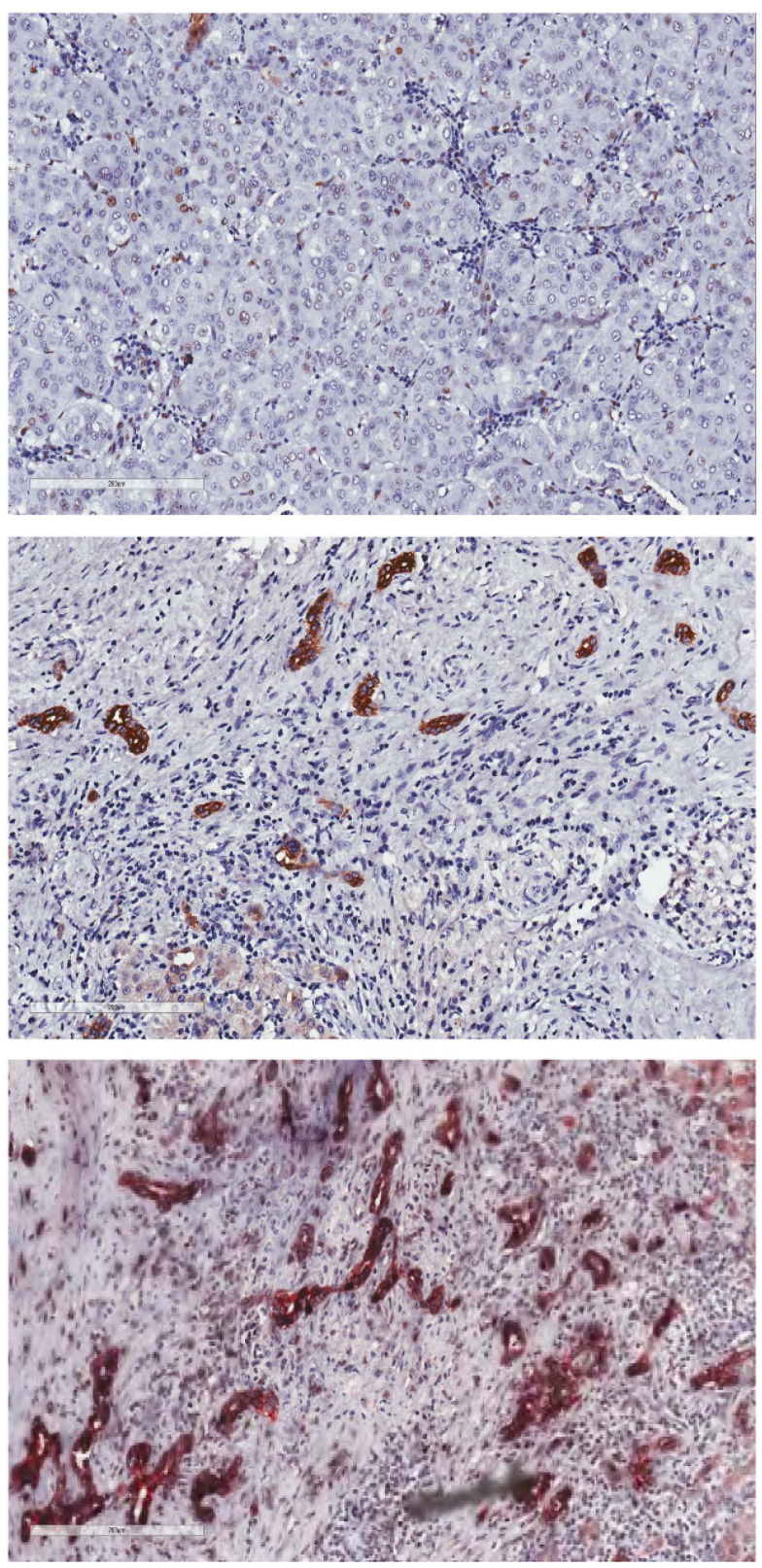

Figure 3. Cont. 

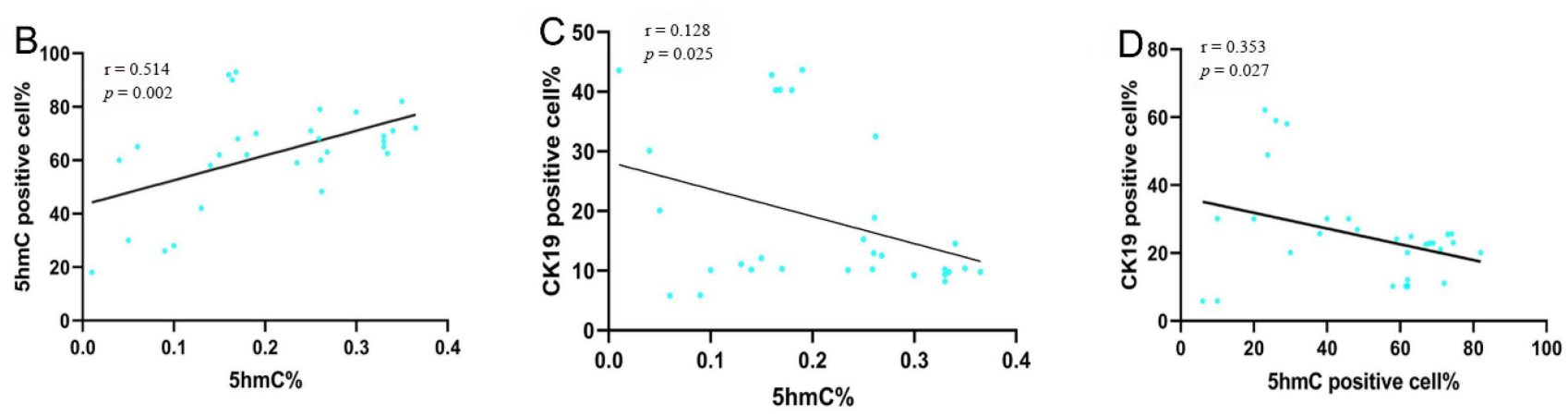

Figure 3. The 5hmC and CK19 IHC staining in metastasis SHCC tumor tissues and para-tumor tissues. Typical image for 5hmC and CK19 staining of metastasis SHCC samples and normal tissue (paired tissue samples from same patient) (A). Pearson's correlation of 5hmC nuclear positive cells with global 5hmC content (B). Pearson's correlation of CK19 cells with global 5hmC content (C). Pearson correlation of CK19 with 5hmC nuclear positive cells (D). Scale bars denote $200 \mu \mathrm{m}$.

Pearson correlation analysis proved that $5 \mathrm{hmC}$ level was positively related to $5 \mathrm{hmC}^{+}$ cell proportion $(r=0.514, p<0.002)$ (Figure 3B). Upon analyzing relationship of the proliferation of SHCC cells with $5 \mathrm{hmC}$ content via CK19 staining, we discovered that $5 \mathrm{hmC}^{+}$cells were negatively related to the CK19-positive cells $(r=-0.353, p=0.027)$ (Figure 3D). Similarly, 5hmC contents were negatively linked to CK19-positive cells $(r=-0.128, p=0.025)$ (Figure $3 \mathrm{C}$ ). Research revealed the correlation of $5 \mathrm{hmC}$ content with cell proliferation.

\subsection{Reduced 5hmC and CK195hC+ within SHCC Genomic DNA concerning Patients' Poor Prognosis}

OS and DFS could be utilized to be the clinical endpoints in assessing the prognostic significance for $5 \mathrm{mC}, 5 \mathrm{fC}, 5 \mathrm{hmC}$, and CK195 ${ }^{5 \mathrm{hC}+}$. Apart from $5 \mathrm{hmC}$ content, $\mathrm{CK} 19^{5 \mathrm{hmC}+}$ content also had a correlation with prognosis (our results did not reveal the correlation between $5 \mathrm{mC}$ and $5 \mathrm{fC}$ contents, so relevant data were not shown here). Patients having low $5 \mathrm{hmC}$ or $\mathrm{CK} 19^{5 \mathrm{hmC}+}$ content exhibited poor OS and DFS relative to counterparts with increased $5 \mathrm{hmC}$ and $\mathrm{CK} 19^{5 \mathrm{hmC}+}$ contents, respectively (Figure 4).
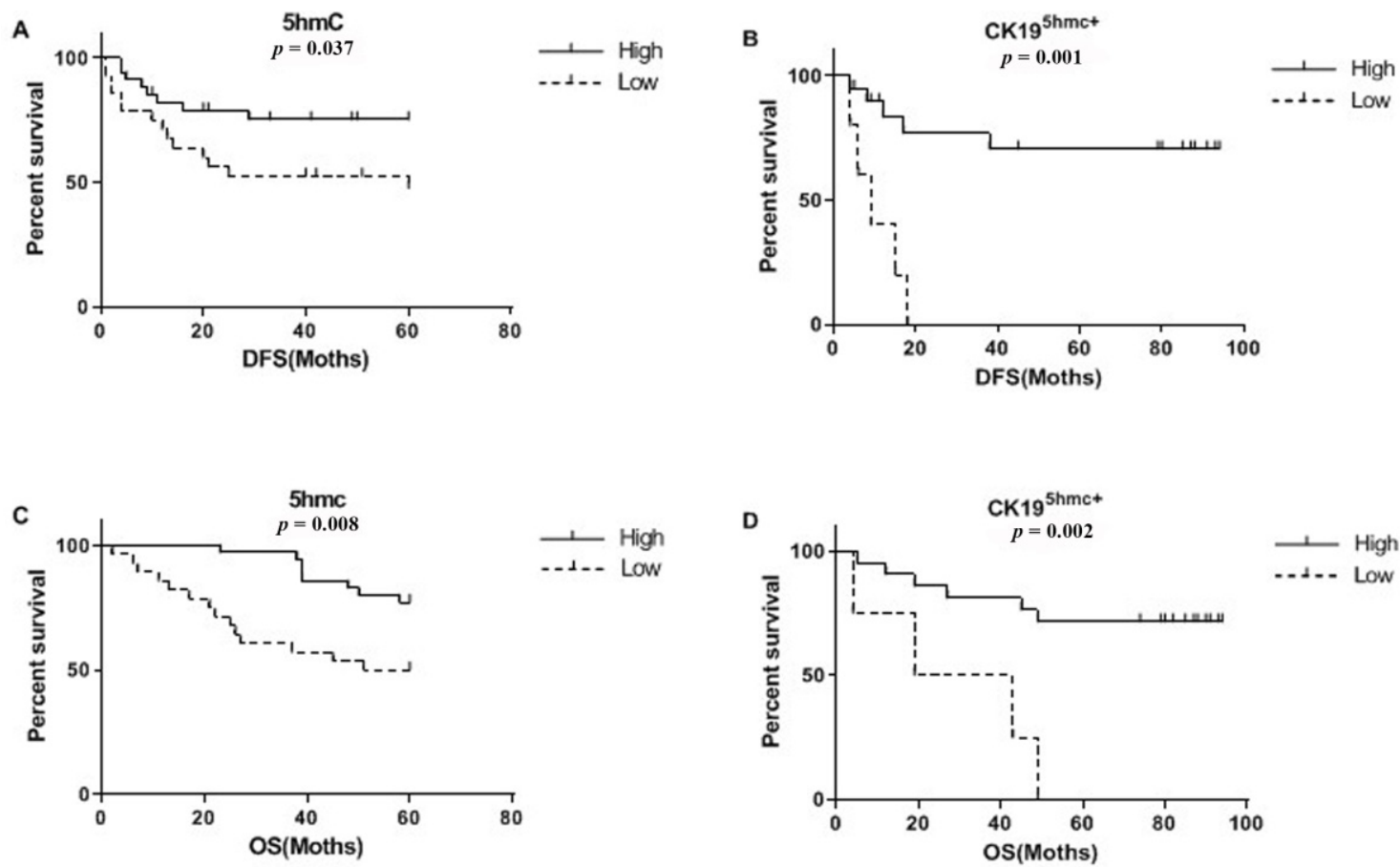

Figure 4. Kaplan-Meier curves which compares DFS and OS of $5 \mathrm{hmC}$ content and CK195hmC+ content from genomic DNA. Patients having low $5 \mathrm{hmC}$ content or CK19 ${ }^{5 \mathrm{hmC}+}$ content in SHCC tissues exhibited poor DFS (A,B) and OS (C,D) relative to counterparts having increased $5 \mathrm{hmC}$ and $\mathrm{CK} 19^{5 \mathrm{hmC}+}$ levels. 


\section{6. $5 \mathrm{hm} \mathrm{C}$ and $\mathrm{CK} 19^{5 \mathrm{hm} \mathrm{C}+}$ Contents Were the Independent Prognostic Factors}

Results from univariate analysis (Table 2) showed that low $5 \mathrm{hmC}$ content (DFS:HR $=4.054$; 95\% CI, 1.037-15.854; $p=0.044$, OS: HR $=3.274 ; 95 \%$ CI, 1.038-10.325; $p=0.043$ ) and CK19 ${ }^{5 \mathrm{hmC}+}$ content (DFS:HR $=0.056 ; 95 \%$ CI, 0.012-0.267; $p=0.000$, OS: HR $=0.152$; $95 \%$ CI, 0.051-0.449; $p=0.001$ ) as well as cirrhosis (DFS:HR $=0.243 ; 95 \%$ CI, $0.072-0.818$; $p=0.022$, OS: $\mathrm{HR}=4.131 ; 95 \% \mathrm{CI}, 1158-14.740 ; p=0.029)$ were linked to worse DFS and OS, which can be considered as independent prognostic factor. Patients having high HBV DNA exhibited worse OS(OS:HR $=0.313 ; 95 \%$ CI, $0.096-1.016 ; p=0.043)$ instead of DFS $(p=0.084)$.

Table 2. Univariate cox analysis on DFS and OS of SHCC.

\begin{tabular}{|c|c|c|c|c|c|c|}
\hline \multirow{2}{*}{ Variable } & \multicolumn{3}{|c|}{ DFS } & \multicolumn{3}{|c|}{ OS } \\
\hline & Hazard Ratio & $95 \%$ CI & $p$ Value & Hazard Ratio & $95 \%$ CI & $p$ Value \\
\hline 5hmC (high vs. low) & 4.054 & $1.037-15.854$ & 0.024 & 3.274 & $1.038-10.325$ & 0.031 \\
\hline CK19 index $(\geq 20 \%$ vs. $<20 \%)$ & 0.384 & $0.087-1.697$ & 0.207 & 0.239 & $0.032-1.782$ & 0.163 \\
\hline CK195hmC+ (high vs. low) & 0.056 & $0.012-0.267$ & 0.000 & 0.152 & $0.051-0.449$ & 0.001 \\
\hline Tumor size, $\mathrm{cm}(\leq 2$ vs. $2-3)$ & 1.359 & $0.314-5.871$ & 0.681 & 3.274 & $1.038-10.325$ & 0.053 \\
\hline Age, years $(\geq 50$ vs. $<50)$ & 1.429 & $0.432-4.211$ & 0.198 & 1.824 & $0.745-2.984$ & 0.277 \\
\hline $\operatorname{AFP}(\mathrm{mg} / \mathrm{mL})(>25 \mathrm{vs} . \leq 25)$ & 1.528 & $0.496-4.708$ & 0.460 & 2.348 & $0.760-7.251$ & 0.138 \\
\hline HBV DNA(IU $/ \mathrm{mL})\left(\geq 10^{3}\right.$ vs. $\left.<10^{3}\right)$ & 0.322 & $0.089-1.165$ & 0.084 & 0.313 & $0.096-1.016$ & 0.043 \\
\hline Cirrhosis (Yes vs. NO) & 0.243 & $0.072-0.818$ & 0.022 & 4.131 & $1.158-14.740$ & 0.029 \\
\hline BCLC staging(0 vs. B) & 0.109 & $0.009-1.307$ & 0.180 & 1.219 & $0.230-6.462$ & 0.816 \\
\hline Gender (male vs. female) & 1.347 & $0.641-5.679$ & 0.487 & 1.743 & $0.719-6.857$ & 0.697 \\
\hline
\end{tabular}

$p$ values in italics are statistically significant. Acronyms: SHCC, small hepatocellular carcinoma; AFP, alpha-fetoprotein; CK19, cytokeratin 19; 5hmC, 5-hydroxymethylcytosine; BCLC classification, Barcelona Clinic Liver Cancer classification.

The multivariate Cox proportional hazards analysis has also been constructed. Four factors including $5 \mathrm{hmC}$ content, CK19 ${ }^{5 \mathrm{hmC}+}$ content, Cirrhosis, and HBV DNA level had been included by the analysis. As seen in Table 3,low 5hmC content (DFS: HR = 3.121; 95\% CI, 0.922- 10.627; $p=0.045$, OS: HR = 2.147; 95\% CI, 1.001-8.213; $p=0.039)$ and CK195 ${ }^{5 m C+}$ content $(D F S: H R=0.029 ; 95 \%$ CI, 0.009-0.254; $p=0.021$, OS: HR =0.123; 95\% CI, 0.016-0.327; $p=0.035$ ) were considered as the factors to independently predict OS and PFS. Cirrhosis, and HBV DNA level were not related to DFS or OS.

Table 3. Multivariate cox analysis on DFS and OS of SHCC.

\begin{tabular}{|c|c|c|c|c|c|c|}
\hline \multirow{2}{*}{ Variable } & \multicolumn{3}{|c|}{ DFS } & \multicolumn{3}{|c|}{ OS } \\
\hline & Hazard Ratio & $95 \%$ CI & $p$ Value & Hazard Ratio & $95 \% \mathrm{CI}$ & $p$ Value \\
\hline 5hmC (high vs. low) & 3.121 & $0.922-10.627$ & 0.045 & 2.147 & $1.001-8.213$ & 0.039 \\
\hline CK19 $19^{5 \mathrm{hm}+}$ (high vs. low) & 0.029 & $0.009-0.254$ & 0.021 & 0.123 & $0.016-0.327$ & 0.035 \\
\hline Cirrhosis (Yes vs. NO) & 1.324 & $0.421-3.742$ & 0.201 & 1.426 & $0.455-7.285$ & 0.131 \\
\hline HBV DNA(IU $/ \mathrm{mL})\left(\geq 10^{3}\right.$ vs. $\left.<10^{3}\right)$ & 0.252 & $0.026-1.057$ & 0.198 & 0.198 & $0.045-0.987$ & 0.171 \\
\hline
\end{tabular}

$p$ values in italics are statistically significant. Acronyms: 5hmC, 5-hydroxymethylcytosine; CK19, Cytokeratin 19; SHCC, small hepatocellular carcinoma.

\section{Discussion}

Epigenetic modification is vital in natural development which has frequent changes during tumor occurrence [9]. Many reports reveal that 5hmC deficiency of many cancers plays an important part in pathogenesis [19-24]. Latest research also pays attention to the major effect of $5 \mathrm{hmC}$ on HCC proliferation which is pathophysiologically and clinically significant to HCC patients [25-27], whereas SHCC is the sole friction of the group. However, if $5 \mathrm{hmC}$ content of SHCC alters is still unclear; thus, our study elaborated on the changes in $5 \mathrm{hmC}$ content in SHCC. According to the research, $5 \mathrm{hmC}$ contents from global genomic of SHCC tumor tissues obviously reduced than para-tumor tissues. The results well conformed to former findings concerning reduced $5 \mathrm{hmC}$ contents of other cancers. 
Further, IHC staining indicated the close association of $5 \mathrm{hmC}$ antibody with $5 \mathrm{hmC}$ level, meaning that IHC staining effectively determined the $5 \mathrm{hmC}$ level.

The underlying mechanisms explaining the influence of $\mathrm{HBV}$ on $5 \mathrm{mC}, 5 \mathrm{fC}$ and $5 \mathrm{hmC}$ levels have aroused attention. HBV may affect the expression and activity of TETs and DNMTs $[28,29]$. Existing research suggested the involvement of HBV infection in lowering $5 \mathrm{mC}, 5 \mathrm{fC}$ and $5 \mathrm{hmC}$ levels, verified from existing tests for HBV DNA-integrative cells. The $5 \mathrm{mC}, 5 \mathrm{fC}$ and $5 \mathrm{hmC}$ levels were obviously decreased within integrative cells. Whereas, the obtained result was inaccurate. Therefore, the correlation and mechanism between the two require thorough investigation.

The biomarkers which could effectively predict the prognosis of SHCC are limited; thus, there is an urgent need to propose more trustworthy prognosis markers [3]. Multiple reports had revealed the correlation of $5 \mathrm{hmC}$ contents with associated clinical outcomes of various cancers $[13,19,25,30]$. This study indicated analysis of $5 \mathrm{hmC}$ in SHCC cohorts revealed the remarkable difference between metastatic and non-metastatic SHCC as an important prognostic biomarker. Whereas, it remains questionable about whether the SHCC histological classification can be used for risk stratification, which does not conform to tumor grading for patients' outcomes [3,31]. At present, DNA amplification as well as methylation patterns may forecast clinical results in HCC patients [3,25]. This research demonstrates high $5 \mathrm{hmC}$ content acts as the prognostic factor to independently predict $\mathrm{OS}$ and PFS of SHCC. On the contrary, low $5 \mathrm{hmC}$ content of many solid tumors often suggests greater tumor grade as well as poor outcomes $[3,11,13,19,25,32]$. Whereas, the research showed the correlation of high $5 \mathrm{hmC}$ contents with good OS of SHCC, and $5 \mathrm{hmC}$ is linked to tumor occurrence or malignant transformation. Nevertheless, the results still request further investigations.

Advance of early diagnosis and treatment for SHCC constitutes a bottleneck which restricts the progress in liver surgery. Thus, novel theories as well as concepts for SHCC diagnosis are urgently needed to instruct medical practice. Modern tumor molecular biology research has defined tumor as a genetic illness arising from long-run accumulation and multi-gene mutations [5]. HCC displays an increased CpG methylation level. Apart from CpG hyper-methylation, global H3K27me3 and DNA methylation reduce devoid of recurrent genetic variations of HCC, suggesting epigenetic mechanisms constitute the core in occurrence [33-39]. Several reports suggest that epigenetics deregulate reduced H3K27me3 $[27,40]$. The research reveals the difference of $5 \mathrm{hmC}$ content between metastasis and non-metastasis in SHCC, implying 5hmC's involvement in aberrant DNA methylation. Thus epigenetic alternation mechanisms need more attention in future studies.

For HCC, CK19 serves as the biomarker for hepatic progenitor cells which plays an important role in cancer migration to indicate bad prognostic outcome [41]. Recently, lots of research works have demonstrated the special biological features of CK19-positive HCC in cancer stem cells (CSCs), invasion, apoptosis, and angiogenesis of cancer cells [42-46]. CK19 has a close relationship with epithelial-mesenchymal transition (EMT), cells positive for CK19 obtain the mesenchymal phenotype via EMT and have strong proliferation because the TGF $\beta$ /Smad signaling is activated [47]. Whereas, the correlation of CK19 expression with DNA methylation in HCC remains unknown. Some studies revealed that lower content of 5hmC or higher level of CK19 was possibly unfavorable prognosis [18,48-51]. However, in this study, $5 \mathrm{hmC}$ content of SHCC was in a negative correlation with CK19 expression. The research verifies former results, indicating low $5 \mathrm{hmC}$ content or CK19 $9^{5 \mathrm{hmC}+}$ content may relevant to poor results. What is more, a large amount of research work has demonstrated the negative relationship between $5 \mathrm{hmC}$ content and cell function in different cancers and CSCs $[13,19,25,26]$. This was also consistent with the result in our study. It has been reported that the methylation levels related to CpG islands in CK19 promoter region were higher in leiomyoma in comparison with neighboring myometrial tissue, indicating the prominent effect of DNA hypermethylation on leiomyoma pathogenesis. It is reasonable to believe that $5 \mathrm{hmC}$ affecting the biological behavior of SHCC cells by modulating the methylation status of CK19, although more investigation needs to be 
conducted to verify our hypothesis. In addition, using combination of CK19 and 5hmC, we might achieve higher accuracy in predicting prognosis and aggressive behavior of SHCC given the crucial of CK19 in tumor cell invasion.

The research has multiple restrictions. First, small sample size and short followup duration restricted the researcher's capacity to seek valid survival predictive factors. More studies should be made to verify the research results. Next, IHC was adopted for categorizing the molecular subgroup. Nevertheless, fresh frozen tumor samples must be introduced, along with methylation arrays.

\section{Conclusions}

The current research suggested that $5 \mathrm{hmC}$ was probably a prospective prognosis predictive factor which facilitated clinical risk stratification in SHCC. Moreover, $5 \mathrm{hmC}$ content was associated with cell proliferation as well as molecular subgrouping. As indicated by final conclusions, the potential regulatory mechanisms for $5 \mathrm{hmC}$ possibly presented new thinking for following treatments.

Author Contributions: J.J. was responsible for funding, statistical analysis as well as drafting of the manuscript. T.Y. carried out bioinformatic analysis and joined in manuscript drafting. F.G. proposed the research conception, and joined in research design, coordination, data analysis, and manuscript drafting. All authors have read and agreed to the published version of the manuscript.

Funding: The research gained financial support from the Youth Fund of National Natural Science Foundation Projects (Grant Number 81802106); National Natural Science Foundation in China (Grant Number 81472610 and 81672310); Postdoctoral Science Foundation Funded Project in China (Grant Number 2019M661523) and the PhD Research Found and the Cultivation Found of the National Natural Science Foundation in Renji Hospital (Grant Number 2019NYBSZX10 and 2019GZRPYMS04).

Institutional Review Board Statement: This research follows the Code of Ethics of the World Medical Association (Declaration of Helsinki). Approval from the ethics committee at Shanghai Renji Hospital, Shanghai Jiaotong University (RA-2020-361) was obtained.

Informed Consent Statement: Informed consent had been provided by patients.

Data availability Statement: The data presented in this study are available in this article.

Conflicts of Interest: The authors declare no conflict of interest.

\section{List of Abbreviations}

5mC: 5-methylcytosine; 5hmC: 5-hydroxymethylcytosine; 5fC: 5-formylcytosine; 5caC: 5carboxylcytosine; DNMTs: DNA methyltransferases; TET: ten-eleven translocation; CK19: Cytokeratin 19; SHCC: small hepatocellular carcinoma; BCLC staging: Barcelona Clinic Liver Cancer staging; TNM: tumor, node and metastasis; DFS: disease-free survival; OS: overall survival.

\section{References}

1. Forner, A.; Reig, M.; Bruix, J. Hepatocellular carcinoma. Lancet 2018, 391, 1301-1314. [CrossRef]

2. Siegel, R.L.; Miller, K.D.; Jemal, A. Cancer statistics, 2020. CA Cancer J. Clin. 2020, 70, 7-30. [CrossRef]

3. Civan, J.M. Management of Small Hepatocellular Carcinoma. Radiology 2016, 279, 651-652. [CrossRef]

4. Hyun, D.; Cho, S.K.; Shin, S.W.; Rhim, H.; Koh, K.C.; Paik, S.W. Treatment of small hepatocellular carcinoma $(\leq 2 \mathrm{~cm})$ in the caudate lobe with sequential transcatheter arterial chemoembolization and radiofrequency ablation. Cardiovasc. Interv. Radiol. 2016, 39, 1015-1022. [CrossRef]

5. Llovet, J.M.; Bruix, J. Molecular targeted therapies in hepatocellular carcinoma. Hepatology 2008, 48, 1312-1327. [CrossRef]

6. Giannini, E.G.; Savarino, V. Platelet count and survival of patients with compensated cirrhosis and small hepatocellular carcinoma treated with surgery. Hepatology 2014, 59, 1649. [CrossRef]

7. Tsujita, E.; Yamashita, Y.-I.; Takeishi, K.; Matsuyama, A.; Maeda, T.; Tsutsui, S.-I.; Matsuda, H.; Ishida, T. The clinicopathological impact of gross classification on solitary small hepatocellular carcinoma. Hepato-Gastroenterol. 2013, 60, 1726-1730.

8. Dai, H.; Cui, D.; Li, D.; Zhai, B.; Zhang, J.; Zhang, J. Hepatic abscess with hepatobronchial fistula following percutaneous radiofrequency ablation for hepatocellular carcinoma: A case report. Oncol. Lett. 2015, 9, 2289-2292. [CrossRef] 
9. Tam, W.L.; Weinberg, R.A. The epigenetics of epithelial-mesenchymal plasticity in cancer. Nat. Med. 2013, 19, 1438-1449. [CrossRef]

10. Liu, J.; Cui, X.; Jiang, J.; Cao, D.; He, Y.; Wang, H. Uncoordinated expression of DNA methylation-related enzymes in human cancer. Epigenetics Chromatin 2017, 10, 1-9. [CrossRef]

11. Storebjerg, T.M.; Strand, S.H.; Høyer, S.; Lynnerup, A.-S.; Borre, M.; Ørntoft, T.F.; Sørensen, K.D. Dysregulation and prognostic potential of 5-methylcytosine $(5 \mathrm{mC}), 5$-hydroxymethylcytosine $(5 \mathrm{hmC}), 5$-formylcytosine (5fC), and 5-carboxylcytosine (5caC) levels in prostate cancer. Clin. Epigenetics 2018, 10, 1-16. [CrossRef]

12. Kantidze, O.L.; Razin, S.V. 5-Hydroxymethylcytosine in DNA repair: A new player or a red herring? Cell Cycle 2017, 16, 1499-1501. [CrossRef] [PubMed]

13. Tucker, D.W.; Getchell, C.R.; McCarthy, E.T.; Ohman, A.W.; Sasamoto, N.; Xu, S.; Ko, J.Y.; Gupta, M.; Shafrir, A.; Medina, J.E. Epigenetic reprogramming strategies to reverse global loss of 5-hydroxymethylcytosine, a prognostic factor for poor survival in high-grade serous ovarian cancer. Clin. Cancer Res. 2018, 24, 1389-1401. [CrossRef] [PubMed]

14. Rodger, E.J.; Chatterjee, A.; Morison, I.M. 5-hydroxymethylcytosine: A potential therapeutic target in cancer. Epigenomics 2014, 6, 503-514. [CrossRef] [PubMed]

15. Spruijt, C.G.; Gnerlich, F.; Smits, A.H.; Pfaffeneder, T.; Jansen, P.W.; Bauer, C.; Münzel, M.; Wagner, M.; Müller, M.; Khan, F. Dynamic readers for 5-(hydroxy) methylcytosine and its oxidized derivatives. Cell 2013, 152, 1146-1159. [CrossRef] [PubMed]

16. Llovet, J.M.; Villanueva, A.; Lachenmayer, A.; Finn, R.S. Advances in targeted therapies for hepatocellular carcinoma in the genomic era. Nat. Rev. Clin. Oncol. 2015, 12, 408-424. [CrossRef] [PubMed]

17. Govaere, O.; Komuta, M.; Berkers, J.; Spee, B.; Janssen, C.; de Luca, F.; Katoonizadeh, A.; Wouters, J.; van Kempen, L.C.; Durnez, A. Keratin 19: A key role player in the invasion of human hepatocellular carcinomas. Gut 2014, 63, 674-685. [CrossRef]

18. Gian Paolo, C.; Michela, C.; Antonella, O.; Patrizia, C.; Emanuela, R.; Chiara, R.; Maria Lorena, A.; Alessandra, R.; Davide Giuseppe, R.; Francesco, T. Prognostic Role of Serum Cytokeratin-19 Fragment (CYFRA 21-1) in Patients with Hepatocellular Carcinoma. Cancers 2020, 12, 2776.

19. Matthias, W.; Liou, W.; Pulverer, W.; Singer, C.F.; Rappaport-Fuerhauser, C.; Kandioler, D.; Egger, G.; Weinhäusel, A. Cytosine 5-hydroxymethylation of the LZTS1 gene is reduced in breast cancer. Transl. Oncol. 2013, 6, 715-721, IN24-IN27. [CrossRef]

20. Jeschke, J.; Collignon, E.; Fuks, F. Portraits of TET-mediated DNA hydroxymethylation in cancer. Curr. Opin. Genet. Dev. 2016, 36, 16-26. [CrossRef]

21. Wang, K.C.; Kang, C.H.; Tsai, C.Y.; Chou, N.H.; Tu, Y.T.; Li, G.C.; Lam, H.C.; Liu, S.I.; Chang, P.M.; Lin, Y.H. Ten-eleven translocation 1 dysfunction reduces 5-hydroxymethylcytosine expression levels in gastric cancer cells. Oncol. Lett. 2018, 15, 278-284. [CrossRef]

22. Sowers, J.L.; Johnson, K.M.; Conrad, C.; Patterson, J.T.; Sowers, L.C. The role of inflammation in brain cancer. Inflamm. Cancer 2014, 816, 75-105.

23. Lewis, K.A.; Tollefsbol, T.O. The influence of an epigenetics diet on the cancer epigenome. Epigenomics 2017, 9, 1153-1155. [CrossRef]

24. Lin, J.; Qin, H.; Wu, W.; He, S.; Xu, J.-h. Vitamin C protects against UV irradiation-induced apoptosis through reactivating silenced tumor suppressor genes p21 and p16 in a Tet-dependent DNA demethylation manner in human skin cancer cells. Cancer Biother. Radio 2014, 29, 257-264. [CrossRef]

25. Liu, J.; Jiang, J.; Mo, J.; Liu, D.; Cao, D.; Wang, H.; He, Y.; Wang, H. Global DNA 5-hydroxymethylcytosine and 5-formylcytosine contents are decreased in the early stage of hepatocellular carcinoma. Hepatology 2019, 69, 196-208. [CrossRef]

26. Sajadian, S.O.; Ehnert, S.; Vakilian, H.; Koutsouraki, E.; Damm, G.; Seehofer, D.; Thasler, W.; Dooley, S.; Baharvand, H.; Sipos, $\mathrm{B}$. Induction of active demethylation and $5 \mathrm{hmC}$ formation by 5 -azacytidine is TET2 dependent and suggests new treatment strategies against hepatocellular carcinoma. Clin. Epigenetics 2015, 7, 1-14. [CrossRef]

27. Hlady, R.A.; Sathyanarayan, A.; Thompson, J.J.; Zhou, D.; Wu, Q.; Pham, K.; Lee, J.H.; Liu, C.; Robertson, K.D. Integrating the epigenome to identify drivers of hepatocellular carcinoma. Hepatology 2019, 69, 639-652. [CrossRef]

28. Lei, J.-C.; Gong, W.-D.; Zhao, Y.; Jiang, H.; Liu, Z.-X.; Yi, J. The influences of Tet system on activity and tissue specificity of HBV Cp. CN J. Cell Mol. Immunol. 2009, 25, 1103-1105.

29. Ogura, N.; Watashi, K.; Noguchi, T.; Wakita, T. Formation of covalently closed circular DNA in Hep38. 7-Tet cells, a tetracycline inducible hepatitis B virus expression cell line. Biochem. Biophys Res. Commun. 2014, 452, 315-321. [CrossRef] [PubMed]

30. Cheng, X.J.; Lin, J.C.; Tu, S.P. Etiology and prevention of gastric cancer. Gastrointest Tumors 2016, 3, 25-36. [CrossRef]

31. Afify, S.M.; Hassan, G.; Osman, A.; Calle, A.S.; Nawara, H.M.; Zahra, M.H.; El-Ghlban, S.; Mansour, H.; Alam, M.J.; Abu Quora, H.A. Metastasis of cancer stem cells developed in the microenvironment of hepatocellular carcinoma. Bioengineering $2019,6,73$. [CrossRef]

32. Chatterjee, B.; Lin, M.-H.; Chen, C.-C.; Peng, K.-L.; Wu, M.-S.; Tseng, M.-C.; Chen, Y.-J.; Shen, C.-K.J. DNA Demethylation by DNMT3A and DNMT3B in vitro and of Methylated Episomal DNA in Transiently Transfected Cells. BBA-Gene Regul. Mech. 2018, 1861, 1048-1061. [CrossRef] [PubMed]

33. Vertino, P.M.; Wade, P.A. R loops: Lassoing DNA methylation at CpGi. Mol. Cell 2012, 45, 708-709. [CrossRef] [PubMed]

34. Hasegawa, R.; Fujiwara, K.; Obinata, D.; Kawashima, H.; Shinojima, Y.; Igarashi, J.; Wang, X.; Ghosh, S.; Nagase, H.; Takahashi, S. Identification of frequent differentially methylated region in sporadic bladder cancers. Urol. Int. 2015, 94, 479-484. [CrossRef] 
35. Makise, N.; Sekimizu, M.; Kubo, T.; Wakai, S.; Watanabe, S.i.; Kato, T.; Kinoshita, T.; Hiraoka, N.; Fukayama, M.; Kawai, A. Extraskeletal osteosarcoma: MDM 2 and H3K27me3 analysis of 19 cases suggest disease heterogeneity. Histopathology 2018, 73, 147-156. [CrossRef]

36. Katz, L.M.; Hielscher, T.; Liechty, B.; Silverman, J.; Zagzag, D.; Sen, R.; Wu, P.; Golfinos, J.G.; Reuss, D.; Neidert, M.C. Loss of histone H3K27me3 identifies a subset of meningiomas with increased risk of recurrence. Acta Neuropathol. 2018, 135, 955-963. [CrossRef]

37. Iwagawa, T.; Watanabe, S. Molecular mechanisms of H3K27me3 and H3K4me3 in retinal development. Neurosci. Res. 2019, 138, 43-48. [CrossRef]

38. Mallol, A.; Guirola, M.; Payer, B. PRDM14 controls X-chromosomal and global epigenetic reprogramming of H3K27me3 in migrating mouse primordial germ cells. Epigenetics Chromatin 2019, 12, 1-10. [CrossRef] [PubMed]

39. Lee, E.; Wang, J.; Jung, Y.; Cackowski, F.C.; Taichman, R.S. Reduction of two histone marks, H3k9me3 and H3k27me3 by epidrug induces neuroendocrine differentiation in prostate cancer. J. Cell Biochem. 2018, 119, 3697-3705. [CrossRef]

40. Hayashi, A.; Yamauchi, N.; Shibahara, J.; Kimura, H.; Morikawa, T.; Ishikawa, S.; Nagae, G.; Nishi, A.; Sakamoto, Y.; Kokudo, N. Concurrent activation of acetylation and tri-methylation of H3K27 in a subset of hepatocellular carcinoma with aggressive behavior. PLoS ONE 2014, 9, e91330. [CrossRef]

41. Durnez, A.; Verslype, C.; Nevens, F.; Fevery, J.; Aerts, R.; Pirenne, J.; Lesaffre, E.; Libbrecht, L.; Desmet, V.; Roskams, T. The clinicopathological and prognostic relevance of cytokeratin 7 and 19 expression in hepatocellular carcinoma. A possible progenitor cell origin. Histopathology 2006, 49, 138-151. [CrossRef] [PubMed]

42. Roskams, T.; Katoonizadeh, A.; Komuta, M. Hepatic progenitor cells: An update. Clin. Liver Dis. 2010, 14, 705-718. [CrossRef] [PubMed]

43. Kim, H.; Choi, G.H.; Na, D.C.; Ahn, E.Y.; Kim, G.I.; Lee, J.E.; Cho, J.Y.; Yoo, J.E.; Choi, J.S.; Park, Y.N. Human hepatocellular carcinomas with "Stemness"-related marker expression: Keratin 19 expression and a poor prognosis. Hepatology 2011, 54, 1707-1717. [CrossRef]

44. Takano, M.; Shimada, K.; Fujii, T.; Morita, K.; Takeda, M.; Nakajima, Y.; Nonomura, A.; Konishi, N.; Obayashi, C. Keratin 19 as a key molecule in progression of human hepatocellular carcinomas through invasion and angiogenesis. BMC Cancer 2016, 16, 1-9. [CrossRef] [PubMed]

45. Yoneda, N.; Sato, Y.; Kitao, A.; Ikeda, H.; Sawada-Kitamura, S.; Miyakoshi, M.; Harada, K.; Sasaki, M.; Matsui, O.; Nakanuma, Y. Epidermal growth factor induces cytokeratin 19 expression accompanied by increased growth abilities in human hepatocellular carcinoma. Lab. Investig. 2011, 91, 262-272. [CrossRef]

46. Ku, N.O.; Strnad, P.; Bantel, H.; Omary, M.B. Keratins: Biomarkers and modulators of apoptotic and necrotic cell death in the liver. Hepatology 2016, 64, 966-976. [CrossRef]

47. Kawai, T.; Yasuchika, K.; Ishii, T.; Katayama, H.; Yoshitoshi, E.Y.; Ogiso, S.; Kita, S.; Yasuda, K.; Fukumitsu, K.; Mizumoto, M. Keratin 19, a cancer stem cell marker in human hepatocellular carcinoma. Clin. Cancer Res. 2015, 21, 3081-3091. [CrossRef]

48. Gillanders, W.E.; Mikhitarian, K.; Hebert, R.; Mauldin, P.D.; Palesch, Y.; Walters, C.; Urist, M.M.; Mann, G.B.; Doherty, G.; Herrmann, V.M. Molecular detection of micrometastatic breast cancer in histopathology-negative axillary lymph nodes correlates with traditional predictors of prognosis: An interim analysis of a prospective multi-institutional cohort study. Ann. Surg. 2004, 239, 828. [CrossRef]

49. Lee, K.; Lee, K.; Jung, H.; Yi, N.; Lee, K.; Suh, K.; Jang, J. The correlation between poor prognosis and increased yes-associated protein 1 expression in keratin 19 expressing hepatocellular carcinomas and cholangiocarcinomas. BMC Cancer 2017, 17, 1-9. [CrossRef]

50. Saloustros, E.; Mavroudis, D. Cytokeratin 19-positive circulating tumor cells in early breast cancer prognosis. Future Oncol. 2010, 6, 209-219. [CrossRef]

51. Yoon, S.O.; Kim, Y.T.; Jung, K.C.; Jeon, Y.K.; Kim, B.-H.; Kim, C.-W. TTF-1 mRNA-positive circulating tumor cells in the peripheral blood predict poor prognosis in surgically resected non-small cell lung cancer patients. Lung Cancer 2011, 71, 209-216. [CrossRef] [PubMed] 